\title{
AS TRANSFORMAÇÕES SOCIOAMBIENTAIS DA PAISAGEM RURAL A PARTIR DE UM DESASTRE AMBIENTAL (PARANÁ, 1963)
}

Social and environmental transformations of the rural landscape after an environmental disaster (Paraná, Brazil, 1963)

\author{
LETÍCIA APARECIDA PAIXÃO E \\ ANGELO APARECIDO PRIORI
}

http://dx.doi.org/10.1590/S0103-21862015000200006

Letícia Aparecida Paixão é mestre em História na linha de Política e Movimentos Sociais (2015) pela Universidade Estadual de Maringá e membro do Laboratório de Pesquisa em História Política e Movimentos Sociais (LAPPOM) da mesma universidade (leepaixao@gmail.com).

Angelo Aparecido Priori é professor associado do Programa de Pós-Graduação em História e do Departamento de História da Universidade Estadual de Maringá (angelopriori@uol.com.br).

Os autores agradecem à Capes, à Finep e à Fundação Araucária pelo financiamento da pesquisa.

Artigo recebido em 28 de junho e aprovado para publicação em 13 de outubro de 2015. 


\title{
RESUMO
}

0 objetivo deste artigo é analisar as transformações ocorridas na paisagem rural do estado do Paraná na década de 1960. Toma-se como referência um desastre ambiental (incêndio florestal) ocorrido no ano de 1963, que vitimou 110 pessoas e deixou milhares desabrigadas, além de destruir florestas e plantações. A hipótese principal é a de que o desastre foi resultado das relações dos homens com o meio natural. Por isso mesmo, é fundamental dar historicidade a essas relações, para compreender o real significado do evento e a forma como ele está inserido em um contexto mais amplo, marcado pela erradicação dos cafezais na região norte e pelo desflorestamento da região central do estado.

PalaVras-CHAVE: desastres ambientais; cafeicultura; floresta de araucária; incêndios; paisagem; Paraná.

\begin{abstract}
The article analyzes the transformations in the rural landscape of the state of Paraná, Brazil, in the 1960s. Focus is given to the environmental disaster (forest fire) occurred in 1963 which killed 110 persons, left thousands of them homeless, and destroyed forests and crops. The relationship between humans and the environment is the main hypothesis for such a catastrophe. It is thus highly relevant to give historicity to such relationships, in order to understand the true meaning of the event and how it is part of a wider context, marked by the eradication of coffee plantations in the northern region and the deforestation in the central region of the state.
\end{abstract}

KeYwords: environmental disasters; coffee plantations; pine-tree forests; forest fires; landscape; Paraná.

\section{RÉSUMÉ}

Cet article veut analyser les transformations vérifiées dans la campagne de l'état du Paraná dans les années 1960. Pour ce faire, on prend comme référence une catastrophe écologique (feux de forêt) survenue en 1963, qui a tué 110 personnes, a laissé des milliers sans-abri, et a détruit des forêts et des plantations. L'hypothèse principale est que cette catastrophe a été le résultat de la relation des hommes avec l'environnement naturel. Il est donc essentiel de donner de l'historicité de ces relations, à fin de comprendre la signification réelle de cet événement et comment il est inséré dans un contexte plus large, marqué par l'éradication des plantations de café dans la region nord et la déforestation dans la région centrale de l'Etat.

Mots-CLÉs: catastrophes environnementales; café; forêts de pins (araucária); incendies; paysage; Paraná. 


\section{INTRODUÇÃO}

D esastres ambientais podem ser definidos como o resultado de eventos adversos, naturais ou provocados pelo homem sobre um ecossistema, traduzido em danos humanos, materiais e/ou ambientais e em consequentes prejuízos econômicos. De modo geral, os desastres ambientais são determinados a partir da relação entre o homem e a natureza. Resultam das tentativas humanas de dominar a natureza, que em sua maioria acabam derrotadas. Além disso, quando não são aplicadas medidas para a redução dos efeitos dos desastres, a tendência é que a intensidade, a magnitude e a frequência dos impactos aumentem (Kobiyama et al., 2006).

Em 1963, entre os meses de agosto e setembro, ocorreu no Paraná um incêndio florestal sem precedentes na história do estado. Aproximadamente 128 municípios tiveram sua infraestrutura afetada pelo fogo. Lavouras, pastos, casas, animais domésticos e selvagens, vidas humanas e reservas florestais foram consumidas pelas chamas que se espalharam pelo território a uma velocidade de aproximadamente 30 quilômetros por hora. Em fins de agosto a situação do Paraná era de calamidade pública. Incalculáveis riquezas foram queimadas, famílias ficaram desempregadas, desabrigadas, doentes e famintas. Essas pessoas passaram a integrar um novo contingente de homens "sacrificados": os "flagelados".

A culpa imediata dos incêndios recaiu sobre a soma de três fatores: estiagem, geada e queimadas de limpeza. A longa estiagem, somada às geadas ocorridas naquele ano, criou uma paisagem de alta e fácil combustão que possibilitou que o fogo se alastrasse rapidamente pelo território devido à ação dos ventos, que propagaram as fagulhas. Quando as primeiras chamas surgiram, não puderam ser facilmente controladas. Essa justificativa imediata para os incêndios não considerava, porém, a conjuntura social, política, econômica e ambiental, que foi determinante para que o evento se tornasse de fato um desastre ambiental. Naquele momento ocorriam no Paraná dois processos distintos: o de colonização de novas áreas agrícolas na região oeste, responsável pelo desmatamento em grandes proporções, e o de erradicação e racionalização da cafeicultura no norte do estado, que liberava terras para novas culturas temporárias e pastagens.

Ao analisar os incêndios ocorridos no território paranaense não podemos tomá-los

como um fato isolado. É preciso, ao contrário, inseri-los em uma conjuntura ampla. Culpar o 
quadro climatológico do período, bem como a prática de queimada no campo, método ainda utilizado por diversos lavradores e por usinas de produção de açúcar e álcool, não parece ser uma resposta suficiente. Para compreender a forma e o significado que esse evento adquiriu é necessário buscar quadros explicativos mais amplos, analisar suas especificidades e, ainda, as características ecológicas, sociais, políticas e culturais da sociedade envolvida.

Em primeiro lugar, é preciso analisar a transformação que a paisagem do território paranaense sofreu a partir do processo de ocupação, bem como da introdução da cultura do café. A cafeicultura foi ganhando espaço, e florestas foram derrubadas para dar lugar às cidades e cafezais. À medida que os solos se esgotavam e a demanda do mercado se intensificava, novas terras passaram a ser exploradas. E à medida que a cobertura vegetal nativa era retirada, os efeitos dos eventos climáticos - as geadas - nos cafezais se tornaram mais intensos.

Em um segundo momento, é necessário analisar a ocorrência dos incêndios dentro da conjuntura da erradicação e racionalização da cultura do café que acontecia na época. $\mathrm{A}$ área liberada pela erradicação dos cafeeiros seria aproveitada para culturas de subsistência, meIhorando o padrão de vida dos produtores e o abastecimento dos centros urbanos, e também para a cultura de outros produtos de exportação capazes de melhorar a receita. Enquanto a região norte do estado passava por esse processo de reocupação das culturas, a região central começava a implantar florestas artificiais. Na década de 1960, restavam poucos remanescentes das florestas de araucária, principal fonte de matéria prima utilizada pela Indústria Klabin, que, em virtude de tal esgotamento, passou a implantar diversas espécies de pinus e eucaliptos para abastecer sua fábrica.

Revisitar os incêndios de 1963 é entender, acima de tudo, que a sociedade produz e reproduz seu espaço de acordo com suas necessidades e com os recursos técnicos e econômicos de que dispõe, mesmo que tais meios resultem em desastres ambientais. Em linhas gerais, devemos compreender a natureza como parte e resultado de uma longa história cultural. Não podemos distanciar e separar seres humanos e natureza.

\section{O CAFÉ E O MODO DE OCUPAÇÃO DA REGIÃO NORTE DO PARANÁ}

Aárea danificada pelo incêndio que desestabilizou as estruturas ambientais, sociais e
econômicas do estado do estado do Paraná em 1963 foi calculada em perto de 21 mil quilômetros quadrados (aproximadamente dois milhões de hectares). 0 incêndio se alastrou por uma extensão ocupada por casas, sítios, lavouras e reservas florestais, gerando um prejuízo de bilhões de cruzeiros e deixando centenas de pessoas desempregadas. Dados oficiais calculam que 2.548 pessoas ficaram desabrigadas, 1.058 feridas e 73 morreram (Paraná, 
1963). Por sua vez, os jornais da época noticiaram que o fogo estava matando em média 10 pessoas por dia, sendo que no dia 9 de setembro 130 lavradores já haviam perdido suas vidas (Última Hora, 9/9/1963: 1). O número de mortos, feridos e desabrigados parece ser impossível de precisar por conta das divergências encontradas nas fontes consultadas. ${ }^{2}$

0 interesse primordial deste texto está vinculado à questão dos incêndios enquanto um desastre ambiental prenunciado. Diversos autores, entre eles Alcántara-Ayala (2002), afirmam que a ocorrência dos desastres está ligada não somente à sua susceptibilidade, devido às características geoambientais, mas também à vulnerabilidade do sistema social sob impacto, isto é, do sistema econômico-social-político-cultural.

A região norte paranaense foi radicalmente transformada, em uma escala sem precedentes. A forma de ocupação e distribuição dos espaços e de utilização da natureza mudou, com a transformação da natureza na abstração da terra e a chegada de homens vindos de outras regiões do país e de outros continentes, com suas culturas e seus hábitos. Nesse sentido, a paisagem de hoje é o resultado da sobreposição de experiências humanas anteriores (Arruda, 2010: 292).

A cafeicultura paranaense foi uma continuação da "marcha para o oeste" do café, e a ocupação do norte do estado foi um fenômeno oriundo da expansão da fronteira agrícola paulista (Cancian, 1981; Priori, 1996). Teve início de forma branda no final do século XIX, quando ocupou primeiramente a região de Jacarezinho, Santo Antônio da Platina, Wenceslau Braz e São José da Boa Vista, e tomou grande impulso a partir de 1920, em decorrência do rápido aumento do preço do café no mercado internacional a partir da Primeira Guerra Mundial (Silveira, 1998: 133).

Esse processo de ocupação resultou da conjunção de vários fatores, entre os quais podem ser destacados a qualidade das terras; a situação econômica nacional no contexto internacional depois da crise de 1929; a evolução da cafeicultura paulista nesse período e, talvez de modo especial, o surto de industrialização de São Paulo a partir da década de 1930. Some-se a isso a proibição de novos cultivos de café pelo governo do estado de São Paulo (Balhana, Machado \& Westphalen, 1969: 83).

No Paraná, além dos fatores mencionados, contribuíram também para o desenvolvimento da economia cafeeira os incentivos do governo do estado à ocupação de terras devolutas de forma permanente e a crise pela qual passava a cafeicultura brasileira, sobretudo a paulista, que desde 1893 vinha adotando medidas restritivas à expansão. Em contrapartida, no mesmo período - fins do século XIX e início do século XX - as autoridades paranaenses procuraram incentivar e proteger a nascente cafeicultura do estado. Em suas mensagens ao Congresso Legislativo estadual em 1904 e 1905, as autoridades pediam não só a redução das taxas como a própria isenção de impostos de exportação por Paranaguá (Oliveira, 2009). 
A cafeicultura paranaense se dinamizou no pós-guerra numa conjuntura diferente das anteriores. Foi a fase de maior vitalidade da expansão cafeeira no estado. 0 centro dinâmico da produção deslocou-se de São Paulo, e o café expandiu a fronteira agrícola do Paraná até a ocupação total das terras disponíveis (Cancian, 1981: 89). Tomando grande impulso na década de 1950, a cafeicultura atingiu na década de 1960 sua fase mais dinâmica. Em 1961, existiam 119.009 propriedades agrícolas no Paraná, das quais 72.337 se dedicavam ao cultivo do café. Como a lavoura e as estradas se situavam nos espigões, "a paisagem era a de um mar ondulante de cafezais rodeando cidades progressistas em função da renda proporcionada pelo café" (Pozzobon, 2006: 92).

Com os altos preços do café, houve uma natural tendência à monocultura, se não de modo generalizado, pelo menos em alguns municípios. A monocultura foi em parte limitada pelo plantio intercalar e pela presença de pastagens, mas todo o norte do Paraná foi tomado por um verdadeiro mar de cafezais, até meados da década de 1960. Nesse momento, devido por um lado à queda dos preços do café em face da superprodução e, por outro, à ação governamental com programas de diversificação agropecuária e industrial, foi se acentuando a diversidade da exploração da terra (Cancian, 1981: 46-47).

Apesar da forte geada de 1942, a área plantada aumentou de 58.870 hectares em 1930 para 113.277 em 1945. 0 Censo Agrícola do Paraná de 1920 e os levantamentos do Departamento Nacional do Café de 1935 e 1942 demonstram que, se por um lado aumentou o número de propriedades que cultivavam café, por outro, diminuiu a área de cultivo em média por fazenda (Oliveira, 2009: 4). ${ }^{3}$

De acordo com Moro (1991: 63), a produção máxima das lavouras de café paranaenses ocorreu por ocasião da safra de 1961/1962, alcançando uma área de 1.620.798 hectares e uma produção de 2.555.155 toneladas, o equivalente a 58,32\% da produção brasileira. Entretanto, ainda segundo o autor, no início da década de 1960 (safra de 1961) sobreveio o problema da superprodução, desequilibrandose a relação entre a oferta e a procura, e instalando-se sobre a cafeicultura brasileira uma acentuada crise de mercado que levou o governo a mudar o rumo de sua política agrícola. Esta foi então orientada, num primeiro momento, para a erradicação de cafeeiros considerados antieconômicos e sua substituição por pastagens e outras culturas. Uma sequência de geadas na década de 1960 resultou na diminuição das safras, mas o fator mais relevante foi a aplicação do Plano de Erradicação de Cafeeiros Antieconômicos - 1962-69, que levou o estoque brasileiro de café a praticamente a zero. A partir de 1969, o Instituto Brasileiro do Café (IBC) passou a incentivar o Plano de Modernização da Cafeicultura, antes relegado a segundo plano em termos de prioridade (Moro, 1991).

Para sistematizar o plano de eliminação da produção excedente foi criado o Grupo Executivo da Racionalização da Cafeicultura (Gerca), com o programa básico de erradicar dois 
bilhões de cafeeiros antieconômicos, procurando ajustar a produção, que era de 36 milhões de sacas, para 24 milhões anuais, sendo 18 milhões para o mercado externo e 6 milhões para o mercado interno (Cancian, 1981).

A meta era erradicar 2 bilhões de cafeeiros antieconômicos no Brasil, visando reduzir a produção e corrigir a estrutura econômica das regiões cafeeiras, com a implantação de agroindústrias para absorver a mão de obra liberada. No período 1962-1967 o Brasil erradicou 2,1 bilhões de pés de café (1,38 bilhão mediante indenização), dos quais 250 milhões só no estado do Paraná - o que liberou áreas para pastagens, milho, arroz, algodão e feijão. Cerca de 35 milhões de pés de café adicionais foram erradicados espontaneamente no estado. Para viabilizar a erradicação, adotou-se uma política de preços baixos responsável também pela eliminação de lavouras produtivas (Pozzobon, 2006: 18).

Em linhas gerais a erradicação foi uma resposta econômica, social e ambiental do período. A estrutura econômica das regiões do Brasil estava profundamente distorcida por conta da monocultura. A plantação extensiva do café, durante muitos anos o único produto com densidade econômica apreciável, relegou a um segundo plano as culturas de subsistência e de demanda do mercado interno. Essa estrutura agrária estava em desacordo com a atualização econômica que o país vivia naquele momento, marcada por um ritmo de crescimento demográfico muito acentuado e por um surto industrial em rápida ascensão. À medida que essas tendências foram se acentuando, mais inadequada se tornou essa estrutura agrária vigente no período (IBC-Gerca, 1962).

A cafeicultura brasileira, de maneira geral, já começava apresentar baixos índices de rendimento e produtividade gerados pelo depauperamento dos solos, pela idade avançada dos cafezais e pelas falhas agronômicas na implantação das lavouras, que influenciaram diretamente na qualidade do café. Tornava-se assim "difícil e antieconômica" a manutenção ou a melhoria das condições de produção dos cafezais (IBC-Gerca, 1962). A racionalização da agricultura foi a forma de defesa encontrada naquela conjuntura. Tratava-se de desfazer os efeitos que os preços altos e os incentivos aos novos plantios haviam provocado na década de 1950, para oferecer ao agricultor uma nova alternativa de renda, com a diversificação da agricultura (Cancian, 1981: 47).

As terras liberadas seriam aproveitadas para as culturas de subsistência, melhorando o padrão de vida dos produtores (sobretudo pequenos agricultores) e o abastecimento dos centros urbanos de consumo, bem como para outros produtos de exportação que melhorassem a receita de divisas. 0 estímulo à industrialização seria uma das constantes do plano em todas as suas fases, bem como a elevação do índice de vida dos trabalhadores rurais, da infraestrutura das regiões produtoras etc. (IBC-Gerca, 1962). 
O principal objetivo era aumentar a produção de alimentos (o que a monocultura do café não proporcionava) assegurando, ao mesmo tempo, o equilíbrio da balança comercial. A produção de café seria realizada para atender aos mercados internacionais, enquanto que a diversificação da produção atenderia ao mercado interno. Nesse período, a tendência dos empresários agrícolas foi diversificar a produção e intensificar a pecuária, sem abandonar, contudo, a cafeicultura, que passou a um plano secundário.

De 1962 a 1969, as pastagens e as lavouras brancas (milho, feijão, arroz, soja e trigo) substituíram os cafeeiros erradicados. Enquanto declinava a participação da cultura cafeeira na economia agrícola paranaense, as lavouras de soja e trigo, estimuladas pelo capital financeiro, tinham sua participação aumentada (Moro, 1991:76).

Verifica-se que a sequência de geadas não foi considerada um fator preponderante para a erradicação dos cafeeiros. A ênfase que a imprensa dava aos prejuízos ocasionados pelas geadas acontecia porque esse fenômeno climático, que é costumeiro na região norte do Paraná, causava prejuízos materiais. Mas o fato a se levar em conta é que grande parte das lavouras de café atingidas não consideraram o limite climático que havia no estado para a expansão do café.

A cultura do café exige uma combinação conveniente de solos e climas. Se os solos do norte paranaense, em grande parte constituídos de terras roxas de excelente qualidade, não ofereciam barreiras ao cultivo do café, o mesmo não se dava com o clima nem sempre favorável de outras regiões do estado (Silveira, 1998:133). 0 clima foi um fator decisivo para limitar a expansão da cafeicultura paranaense. 0 norte do estado possui um clima de transição entre o tipo subtropical e o tropical de altitude do oeste paulista. À medida que "caminhamos para o Sul", a diminuição das temperaturas e a maior frequência e intensidade das geadas vai tornando impraticável a cultura do café (Muller, 2001: 91).

Dos fenômenos climáticos que ocorrem na região, as geadas, devido à cultura do café, se revestem de especial importância. 0 norte do Paraná é atingido por dois tipos de geada: a "branca" e a "preta". A geada branca corresponde a um "golpe de frio" local: devido à irradiação noturna, ocorre a inversão de temperatura, aparecendo então brumas frias e geadas nos vales e depressões territoriais. A geada branca ocorre principalmente no inverno, e é para escapar à sua ação que os cafezais procuram as terras mais altas - no norte do Paraná, de preferência as vertentes ensolaradas, de orientação N (norte) e NW (noroeste). A geada preta ocorre quando a frente polar avança, facilitada pelo recuo da massa tropical-atlântica. 0 encontro das duas massas provoca tempestades, seguidas de bruscas quedas de temperatura: as plantas, carregadas de umidade não evaporada, são então queimadas por congelamento (Muller, 2001: 92). 
De acordo com Muller (2001), o perigo da geada preta para os cafezais é incomparavelmente maior que o da branca: ocorrendo no início do verão, quando as plantas não estão em repouso vegetativo, ela aniquila e mata, comprometendo seriamente a safra. Por várias vezes, principalmente nos anos de 1942, 1953 e 1955, o norte do Paraná foi duramente atingido pela geada preta, fato que comprova estar a região no limite mais meridional em que o café pode ser plantado sem definitivas impossibilidades climáticas.

No período de expansão da cafeicultura no Paraná geadas brancas e negras atingiram em certo grau as lavouras. Maack (1968) referiu-se aos impactos climáticos que poderiam advir em decorrência da devastação das matas pluviais e da sua substituição por cafezais. No início da expansão do café as consequências das geadas não foram tão profundas para as lavouras por conta da cobertura nativa que ainda existia na região. Mas à medida que o desmatamento de vastas áreas nativas deu lugar ao "mar ondulante verde" de café, os danos tornaram-se mais intensos, pois não havia florestas para proteger os cafezais.

\section{Desmatamento: uma CONSEQUÊNCIA DA TRANSFORMAÇÃO DA NATUREZA EM MERCADORIA}

$\mathrm{N}$ ão há como falar da ocupação do território e da expansão do café sem levar em consideração o desmatamento da região. A exploração dos recursos da natureza no território paranaense foi determinada pelo momento econômico vigente, que representou o fio condutor do processo de ocupação e organização espacial. A natureza foi manipulada de acordo com os interesses do capital, e o espaço modificado foi organizado e dotado da infraestrutura necessária para retirar todo o seu aproveitamento.

A devastação da mata subtropical no norte do Paraná foi realizada para o desenvolvimento da agricultura cafeeira. Esta foi, em primeira instância, conduzida pelas companhias colonizadoras de terras que organizaram o processo de povoamento. A troca das matas pelas estradas, da floresta pelos cafezais, dos animais silvestres pela pecuária comercial, ocorreu para promover o desenvolvimento econômico (Fogari, 2009: 11). A decisão do estado também valorizou a escolha do desenvolvimento econômico em detrimento do meio ambiente, o que resultou em uma grande devastação das áreas cobertas por florestas.

Para a formação dos cafezais eram procuradas as terras cobertas de matas de alta fertilidade natural, nas quais eram formadas as lavouras. Ao mesmo tempo em que ocorria o desmatamento das reservas nativas do norte do Estado, as matas - sobretudo as florestas de araucária - de outras regiões já se encontravam em um estágio avançado de devastação. 
Nas últimas décadas do século XIX e primeiras décadas do século XX, a cobertura florestal do Paraná estava praticamente intacta, correspondendo a cerca de $80 \%$ de seu território (Gubert Filho, 2010: 15).

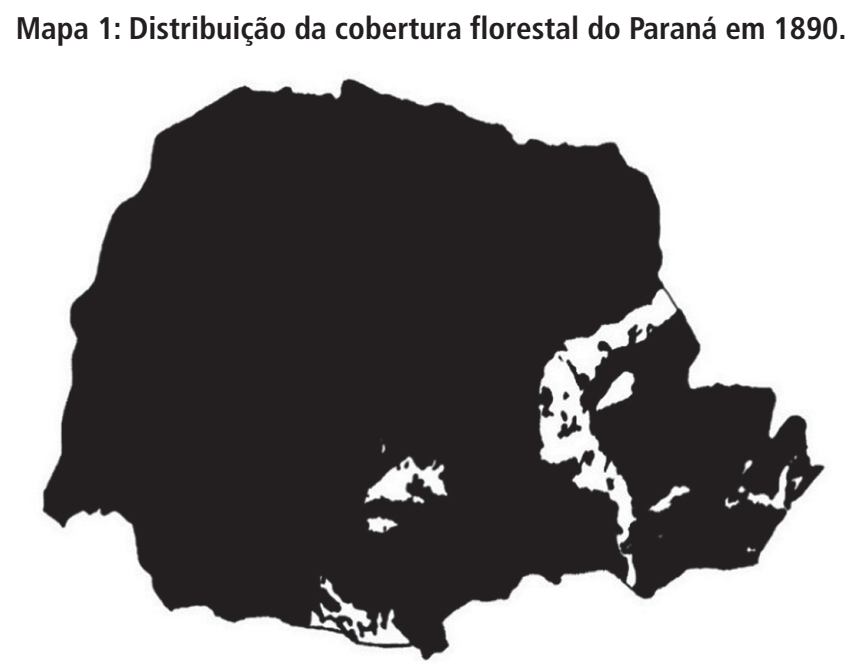

Área florestal: 16.762. 400 ha -83,41\% do estado. Fonte: Gubert Filho, 2010: 19.

Gubert Filho (2010) demonstra como os ciclos econômicos paranaenses influíram diretamente no processo de devastação das matas nativas do estado, uma vez que as atividades econômicas estiveram profundamente relacionadas com o processo de intervenção nas florestas de araucária. 0 autor inicia sua análise com o advento do ciclo madeireiro em 1888, após a inauguração da ferrovia ligando Curitiba ao porto de Paranaguá, quando a ocupação de áreas florestais foi se processando de forma acelerada, a ponto de, por volta de 1900, todo o planalto de Curitiba estar devastado.

Em 1910, com a chegada dos trilhos da Estrada de Ferro São Paulo-Rio Grande a União da Vitória, a atividade extrativa de araucária, imbuia, cedro e canelas foi "abrindo" o sul paranaense, e as serrarias "pipocavam" ao longo da chamada Linha-Sul, entre Ponta Grossa e União da Vitória. Em 1907 o Paraná editou o primeiro Código Florestal do Brasil, mas durante a Primeira Guerra Mundial (1914-18) a indústria do pinho progrediu extraordinariamente, a ponto de a extração da araucária tornar-se desenfreada (Gubert Filho, 2010: 16).

A partir de 1920, passou-se a dizimar imensas regiões de florestas do segundo Planalto paranaense, para a implantação de uma agricultura extensiva. Em 1926, o então deputado estadual Romário Martins alertou para a sistemática dilapidação dos pinhais e propôs um projeto de lei que alterava o Código Florestal do Estado. Esse projeto previa a desapropriação 
de áreas destinadas à perpetuação do sertão paranaense, que seria mantido isento de alteração em sua fisionomia natural, e não permitia qualquer exploração econômica, sendo sua finalidade exclusivamente científica, moral e estética. Mas esse projeto de lei não foi aprovado, e a medida preservacionista, inédita para a época, não foi levada a efeito (Gubert Filho, 2010).

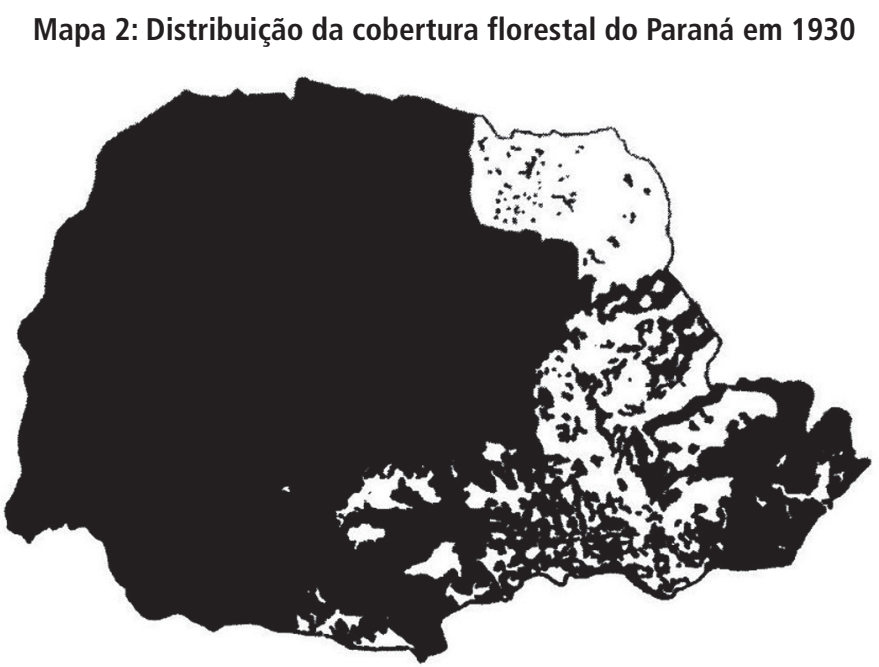

Área florestal: 23. 902. 400 ha $-64,12 \%$ do estado. Fonte: Gubert Filho, 2010: 20.

Em 1945, houve a inauguração da Indústria Klabin, na localidade de Monte Alegre, no município de Telêmaco Borba, que mudou definitivamente a configuração da região da araucária no Paraná. Na década de 1960, essa indústria fornecia praticamente todo o papel de jornal utilizado pela imprensa nacional, com uma produção diária de 350 toneladas, além de outras 150 toneladas de celulose, papel kraft e papelão (Paraná, 1964).

No início de suas atividades, a Klabin consumiu boa parte dos remanescentes de araucária, sua principal matéria-prima. Mas diante de seu esgotamento, passou a fabricar celulose a partir do eucalipto e de várias espécies de pinus. Com o esgotamento da floresta natural, a Klabin começou a pôr em prática um plano de reflorestamento da região, visando garantir matéria-prima para o futuro de suas atividades. Como o aproveitamento industrial-econômico da araucária ocorre entre 20 e 25 anos de idade, a indústria optou pelo cultivo de espécies que dessem um retorno mais rápido, o que levou ao quase desaparecimento das florestas de araucária.

Em 1950, Reinhard Maack publicou um Mapa Fitogeográfico do Estado do Paraná, ${ }^{4} 0$ primeiro do gênero no Brasil. Tal mapa assinalava o rápido recuo da floresta de araucária. 0 primeiro e o segundo planaltos foram caracterizados como "regiões de matas devastadas", e o terceiro planalto aparecia relativamente preservado. 


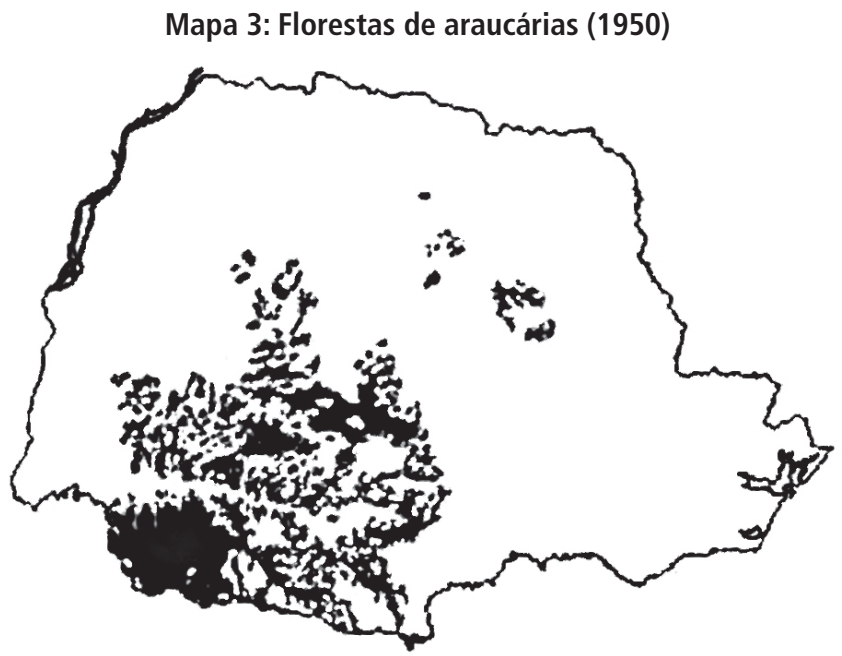

Florestas de araucária, com taquaris e palmáceas (Cocos romanzoffiana predominantes, associados ainda com Euterpe edulis nas regiões mais quentes). Fonte: Valaski \& Nucci, 2006: 7.

Em linhas gerais, o processo de colonização inicial ocorrido no Paraná tradicional consolidou-se até 1930. Tal consolidação foi diretamente proporcional ao desmatamento das florestas de araucária, que praticamente foram reduzidas à metade. Observa-se ainda uma segunda fase de aceleração do desmatamento da floresta de araucária, que pode ser associada à fase inicial da industrialização da agricultura, coincidente também com a aceleração do declínio das florestas no norte paranaense (Hauer, 2010: 35).

Em 1960 Maack ainda conseguiu registrar graficamente o ritmo de modificação da paisagem natural, mas cinco anos depois já não existiam dados precisos, pois as florestas remanescentes do segundo planalto haviam sido atingidas pelo incêndio florestal de 1963, incluindo os reflorestamentos de araucária da indústria Klabin (Gubert Filho, 2010: 18; Klabin, 1963).

É importante ressaltar que, após o incêndio de 1963, a Klabin passou a comprar as "lascas" provenientes das araucárias jovens remanescentes das florestas nativas. Após as derrubadas, as araucárias eram "lascadas ao meio" e embarcadas como lenha. Do sul do Paraná, vagões e vagões de lascas foram destinados à fábrica de celulose em Monte Alegre, gerando uma dilapidação sem precedentes dos pinheirais em regeneração. Mais uma vez, predominou a mentalidade extrativista e predatória (Gubert Filho, 2010).

Somente na década de 1960 o Paraná perdeu cerca de 240 mil ha/ano de florestas. Segundo Maack (1968), da área primitiva de 167.824 km² de florestas existentes no território paranaense, já haviam sido destruídos $119.688 \mathrm{~km}^{2}$, restando, portanto, $48.136 \mathrm{~km}^{2}$, sendo $32.204 \mathrm{~km}^{2}$ da grandiosa floresta pluvial tropical e apenas $15.932 \mathrm{~km}^{2}$ da floresta de araucária. 
Mapa 4: Distribuição da cobertura florestal do Paraná em 1965

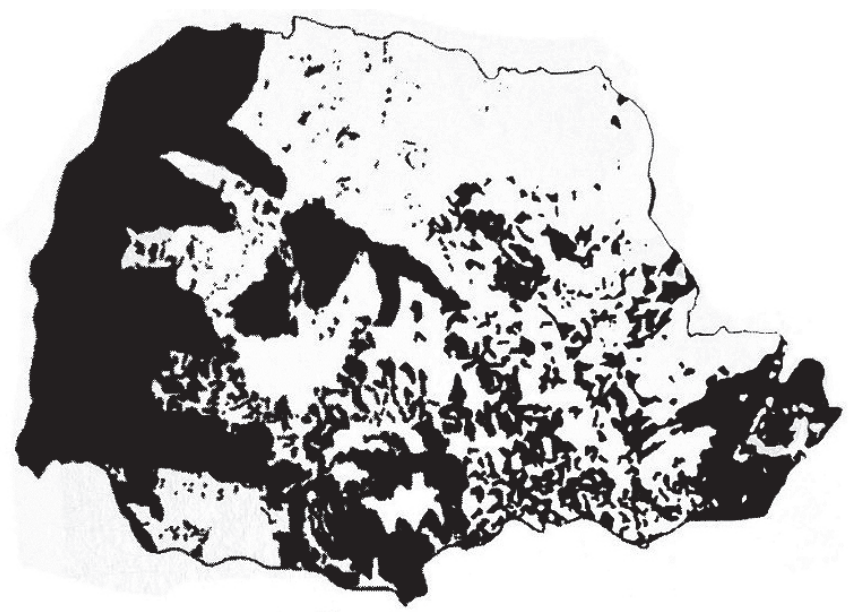

Área florestal: 4.813.600 ha - 23,92\% do estado. Fonte: Gubert Filho, 2010: 22.

Em apenas um século (1890 a 1990) o estado do Paraná reduziu sua cobertura florestal de 16.762 .600 hectares, ou 83,41\% de seu território, para cerca de 872.600 hectares, ou 5,20\% de seu território (Gubert Filho, 2010: 24).

Mapa 5: Distribuição da cobertura florestal do Paraná em 1990

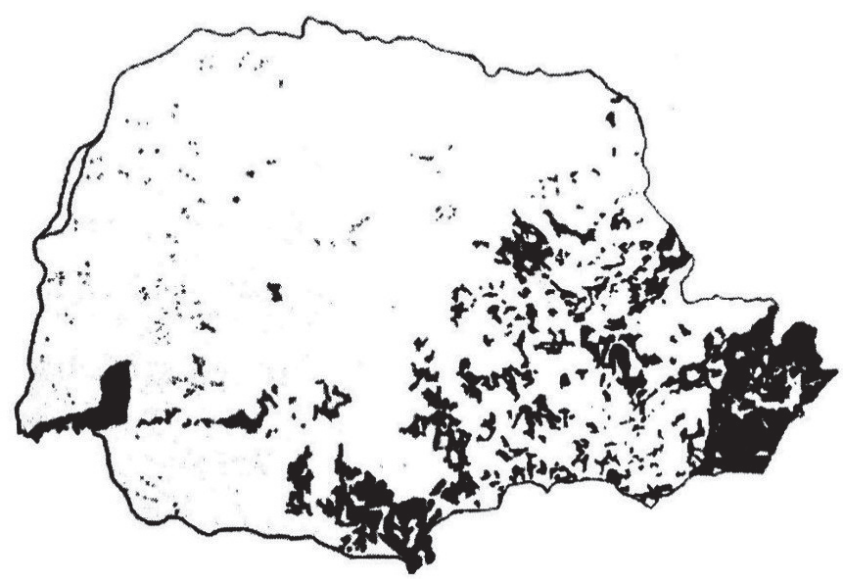

Área de florestal: 872.600 ha $-5,20 \%$ do estado. Fonte: Gubert Filho, 2010: 23.

Atualmente restam remanescentes florestais na Serra do Mar, no Parque Nacional do Iguaçu e ao longo da Escarpa Devoniana e da Serra da Esperança, todos protegidos por Unidade de Conservação (Parques e Áreas de Preservação Permanente - APPs). 
Devemos levar em consideração que nos dias atuais o Brasil publicou um novo Código Florestal (Brasil, Lei n. 12.651 de 25/05/2012), ${ }^{5}$ instituindo regras gerais sobre onde e de que forma o território brasileiro pode ser explorado. Determinou também as áreas de vegetação nativa que devem ser preservadas e quais regiões são legalmente autorizadas a receber os diferentes tipos de produção rural.

O Código Florestal representa uma política pública para controlar o desmatamento desenfreado, classificando como criminoso aquele que pratica tal delito. Porém, mesmo com uma lei em plena vigência, ainda existem práticas criminosas que insistem em espoliar o meio ambiente. Mas qual o motivo da persistência em desrespeitar o meio ambiente e consequentemente as leis de preservação?

Segundo Hauer (2010) há um persistente passivo ambiental, representado pela manutenção dos baixos índices de cobertura florestal e dos processos de erosão e de contaminação ambiental. Para a autora, esse contexto é fruto do modelo de desenvolvimento adotado, que é resiliente às adequações ambientais. ${ }^{6} \mathrm{~A}$ autora conclui que a adoção de metodologias socioambientais apropriadas é incompatível com o modelo de produção agrícola hegemônico, acarretando prejuízo aos resultados esperados pelos projetos de recuperação ambiental e, por consequência, à coletividade.

Os projetos e programas devem envolver os agricultores - que são os atores- alvos das ações e diretamente responsáveis por sua execução em campo. Considerando que a conservação e recuperação ambiental é um processo que requer a consolidação de parcerias, os programas e projetos decorrentes devem ter a participação dos parceiros em sua concepção (Hauer, 2010: 39).

Não se pode negar, porém, que se trata de um desafio que pode estar acima da nossa atual capacidade conjuntural e estrutural, principalmente devido a dois fatores interligados: a propriedade das terras e os modelos de produção. Até porque a grande perda de florestas no Paraná decorreu das intervenções nas grandes propriedades, que era onde se localizavam as grandes áreas florestais. Assim, os proprietários das terras apropriaram-se e dispuseram dos recursos naturais, bem como despojaram-se do poder para influenciar na seleção dos modelos de desenvolvimento (Hauer, 2010).

Os incêndios de 1963 queimaram um total de 2 milhões de hectares no Paraná, sendo 20.000 de plantações, 500.000 de florestas primárias e 1.480.000 de campo, matas secundárias e capoeiras (Soares, 1985: 3). Esse novo cenário no mundo rural e florestal, proporcionado pelos incêndios, trouxe à luz a necessidade do reflorestamento da região de araucária, já que a maior fábrica de papel e celulose da América Latina perdeu grande parte do seu patrimônio florestal, que era utilizado como matéria-prima na linha de produção (Klabin, 1963). Assim 
sendo, a empresa introduziu novas de espécies de pinus ${ }^{\urcorner}$para impulsionar a economia florestal e "preservar" o restante de matas nativas que ainda havia no estado.

A crescente implantação de pinus no Brasil reflete o contexto econômico que o país viveu entre as décadas de 1950 e 1960. Nesse período, discutia-se o modelo de desenvolvimento econômico que deveria ser seguido. Existiam basicamente duas correntes: uma que vislumbrava um modelo de desenvolvimento econômico baseado na substituição das importações e na expansão do mercado doméstico, e outra que sugeria a adoção de um modelo de desenvolvimento orientado para a exportação. 0 modelo seguido pelo setor florestal brasileiro foi o da substituição das importações, sobretudo de papel, pela produção doméstica, de forma a dinamizar a economia nacional (Tuoto \& Hoeflich, 2008: 6).

A adoção de tal modelo acabou por consumir o restante das matas nativas que havia no Paraná. 0 medo do esgotamento da matéria-prima fez com que as fábricas de papel e celulose instaladas no estado, sobretudo a Klabin, se preocupassem com o reflorestamento e até mesmo com a melhoria genética das araucárias. No entanto, esqueceram-se de que em florestas implantadas - principalmente quando há condições climáticas favoráveis - o fogo se alastra com mais facilidade, como enfatiza Ronaldo Soares: "de maneira geral povoamentos implantados são mais sujeitos aos incêndios florestais e oferecem condições mais favoráveis a sua propagação do que os naturais intocados" (1985: 40).

A propagação dos incêndios, embora pareça um processo bem simples quando se observa um pequeno foco de fogo, é na realidade um fenômeno bastante complexo. Os mecanismos que determinam o processo de propagação, principalmente a transferência ou fluxo de calor, são bastante distintos dependendo da intensidade do fogo. Nesse sentido, há uma série de fatores que influem na propagação das chamas. Soares (1985: 39) ressaltou que o material combustível (quantidade, tipo e arranjo) e sua umidade relativa, as condições climáticas, a topografia e o tipo de floresta são fatores determinantes para a propagação de incêndios florestais.

Os incêndios ocorreram devido a uma série de fatores, e não apenas pela equação "seca + geada + queimadas". Obviamente havia um quadro climático que contribuiu para a propagação das chamas, mas para analisar os efeitos gerados pelo fogo em determinadas regiões do estado é preciso entender qual era o contexto do meio natural naquele período. As regiões mais densamente atingidas foram justamente a região cafeeira, que passava por um processo de erradicação liberando espaço para outras culturas, sobretudo para a pastagem, e a região central do estado, onde estavam localizados os remanescentes de florestas nativas e o reflorestamento implantado da indústria Klabin.

Dificilmente se considera a mão do homem no desencadeamento de um desastre ambiental, e quando este gera prejuízos humanos e materiais, as forças da natureza acabam sen- 
do as únicas culpadas por tal tragédia. Nesse sentido, para verificar os desdobramentos que um desastre de curta duração pode ocasionar em uma sociedade, é preciso ter em mente a conjuntura desta, uma vez que tais eventos, que geram efeitos econômicos, sociais, sanitários e ambientais, não podem ter a natureza como a única responsável.

\section{CONSIDERAÇÕES FINAIS}

$\mathrm{O}$ fogo é um agente hidrológico, geomorfológico e ecológico que influencia direta e indiretamente toda a dinâmica ambiental de um ecossistema. Comumente os agricultores utilizam a técnica do fogo para a limpeza da vegetação destinada à agricultura. Método tradicional, de baixo custo e de resultados imediatos, as influências que seu uso pode ocasionar na dinâmica da paisagem, como infiltração, erosão e alteração na dinâmica de matéria orgânica, são desconsiderados.

A queimada de limpeza não pode ser considerada a única causadora do incêndio florestal ocorrido no Paraná em 1963, até porque relatos afirmam que essa prática persistiu em anos anteriores e posteriores, e em nenhum desses casos houve a ocorrência de um incêndio com as mesmas dimensões do daquele ano.

Deve-se levar em consideração que a possibilidade e a frequência da ocorrência de incêndios florestais estão intimamente ligadas às condições atmosféricas locais. Existe uma forte correlação entre ocorrência de grandes incêndios e prolongados períodos de seca, pois longos períodos de estiagem afetam o potencial de propagação dos incêndios de diversas maneiras, principalmente pela secagem progressiva do material combustível morto, podendo inclusive afetar o teor de umidade da vegetação verde. Isso aumenta a probabilidade de ignição e a facilidade de propagação ao incêndio (Soares, 1985: 49-50).

A análise climatológica de 1963 provou que esse ano foi caracterizado por um longo período de estiagem que se iniciou em janeiro e perdurou até o final do mês de setembro. Nesse meio tempo o inverno foi irregular, pois houve períodos de temperaturas elevadas e períodos de frios extremos com ocorrência de geadas em algumas regiões. De fato, o quadro climático contribuiu para as chamas se alastrarem de modo considerável no território paranaense. Mas a justificativa climática também não pode ser a principal culpada ao lado das queimadas. Além das condições atmosféricas, o grau de propagação de incêndios florestais também é medido pela quantidade de material combustível presente no território.

Sobre o material combustível que havia disponível nos solos paranaenses naquele momento, devemos atentar para as transformações que a paisagem vinha sofrendo em anos anteriores. A ocupação e a introdução do café no norte do estado promoveram a devastação 
de extensas áreas da floresta pluvial em um curto espaço de tempo. A implantação da indústria Klabin nas áreas de florestas de araucária também promoveu a devastação da região. Temos então no norte do estado um grande empreendimento fundiário apoiado na cultura do café, e no centro-sul, a instalação da primeira fábrica integrada de produção de papel no Brasil. 0 desmatamento, por ambos os empreendimentos, favoreceu a verticalização da biota e a diminuição de áreas de florestas nativas, reduzindo a umidade e favorecendo a velocidade e propagação dos ventos (Nunes, 2013).

Há que se destacar também que em 1963 a cafeicultura passava pelo processo de erradicação e que estava ocorrendo a racionalização e modernização da agricultura, com a substituição da monocultura do café por outras atividades mais rentáveis. Extensas áreas degradadas ou abandonadas tornaram-se inviáveis para a cafeicultura, dando lugar a outras culturas, mais favoráveis à propagação de incêndios.

0 esquecimento desse desastre ambiental no Paraná é um fato considerável. Há poucas publicações oficiais e poucos relatos nos jornais regionais. Nunes (2013) realizou um trabalho sobre os incêndios no Paraná, e, ao entrevistar diversos sujeitos sociais, estes apontaram o período pré-golpe militar como a principal razão do esquecimento do desastre. 0 autor também entrevistou Armínio Kaiser e questionou o engenheiro agrônomo sobre o fato não haver publicações a respeito dos incêndios. A resposta foi direta: "Não há interesse em mexer nisso. Pra que vamos mexer nessa história? É desagradável, não é?" (Nunes, 2013: 163).

Além desses motivos, acreditamos que falar em tal desastre não interessava muito às autoridades naquele período. Diversas cidades, sobretudo as das regiões mais densamente atingidas, estavam passando pelo processo de ocupação, enquanto a agricultura caminhava para um processo modernizante. Não era interessante para o governo mostrar as "mazelas" do estado, fato que pode ser comprovado quando analisamos as mensagens do Poder Executivo enviadas à Assembleia Legislativa no ano de 1964, nas quais em nenhum momento são citados os incêndios. Se os incêndios não foram lembrados nos anos posteriores, dificilmente poderiam persistir na memória da população. Essa questão precisa ser trabalhada melhor em um momento mais oportuno, pois, como escreveu Lopes (2013), analisar como e por que a lembrança de uma catástrofe é perpetuada ou esquecida frequentemente faz com que se evidencie a complexidade de suas consequências.

Por fim, os incêndios de 1963 no Paraná não aconteceram por acaso. Eles foram produzidos por meio de uma cadeia de escolhas humanas e ocorrências naturais. Foram fruto das relações dos habitantes com seu meio natural. Nesse sentido, desastres ambientais devem ser considerados uma ocorrência social, física e cultural, e não apenas eventos climatológicos. Devem ser vistos como construtos socioculturais. 


\section{NOTAS}

1 Termo usado pela imprensa da época para se referir à população vítima dos incêndios.

2 Os jornais e revistas pesquisados para este artigo foram: Diário da Tarde (Curitiba), Fatos e Fotos (Brasília), Folha de Londrina (Londrina), Folha do Norte (Maringá), Gazeta do Povo (Curitiba), Indústria (Curitiba), Manchete (Rio de Janeiro), O Tibagi (Tibagi/PR), Sinal Verde (Brasília) e Última Hora (Curitiba).

3 Cancian (1981: 69-70) adverte que o quadro recessivo da década de 1930 provocou uma diminuição na área cafeeira dos latifúndios e que houve um incentivo aos minifúndios. Da mesma forma, a autora ressalta que o dinamismo de outrora dos cafeicultores, quando o café batia recordes em preços altos, esteve ausente nesse período.

40 Mapa Fitogeográfico do Estado do Paraná, elaborado por Reinhard Maack em 1950, caracteriza-se como um referencial de geografia física, um dos mais completos mapas já elaborados sobre o Paraná. É extremamente rico em informações, apresentando não somente a cobertura vegetal existente no estado naquele período, como também o uso e a ocupação do solo (Valaski \& Nucci, 2006:3).

50 primeiro Código Florestal do país foi lançado em 1934 (Decreto 23.793) e, entre outras medidas, obrigava os proprietários a preservar $25 \%$ da área de suas terras com a cobertura de mata original. 0 código foi atualizado em 1965 (Lei n. 4.771), prevendo que metade dos imóveis rurais da Amazônia deveria ser preservada. A partir de 1996, o Código Florestal passou a ser modificado por diversas Medidas Provisórias, até ser totalmente reformulado em maio de 2012.

6 As premissas e ações propostas que têm por objetivo solucionar os problemas ambientais muitas vezes não funcionam em sintonia com o cotidiano de determinada sociedade, ou com os processos dinâmicos que hoje existem dentro da natureza e numa economia global. Segundo Daniel Meyer (2014), uma abordagem que afronta esse desafio se encontra no conceito da resiliência, pouco difundido nos estudos, nas produções acadêmicas ou nas discussões ambientais no Brasil. Em 1973, o ecologista canadense C. S. Holling publicou um artigo denominado "Resilience and stability of ecological systems", com a finalidade de criar modelos para entender as mudanças dentro da estrutura e a função dos ecossistemas. 0 autor conseguiu ilustrar a existência de múltiplos domínios e a estabilidade em sistemas naturais, e como esses domínios se relacionam com os processos ecológicos, eventos aleatórios (por exemplo, queimadas e tempestades), em uma larga heterogeneidade de escalas temporais e espaciais (Holling, 1973). Nesse sentido, a resiliência pode ser simplesmente definida como a capacidade de um sistema de absorver distúrbios, choques, e consequentemente manter suas funções e estruturas básicas (Meyer, 2011: 10).

7 Historicamente, espécies de pinus vêm sendo plantadas no Brasil há mais de um século. Muitas delas foram trazidas pelos imigrantes europeus, para fins ornamentais e para a produção de madeira. As primeiras plantações de que se tem notícia foram estabelecidas no Rio Grande do Sul, com Pinus canariensis, provenientes das Ilhas Canárias, em torno de 1880. Em 1948, por iniciativa do Serviço Florestal do Estado de São Paulo, foram introduzidas as espécies americanas conhecidas como "pinheiros amarelos", que incluem $P$. palustris, $P$. echinata, P. elliottii e $P$. taeda. Desde então, outras espécies têm sido introduzidas, não só dos Estados Unidos, mas também do México, das ilhas do Caribe e da Ásia (Shimizu, 2008: 5).

\section{REFERÊNCIAS BIBLIOGRÁFICAS}

ALCÁNTARA-AYALA, Iracema. Geomorphology, natural hazards, vulnerability and prevention disasters in developing countries. Geomorphology, v. 47, p. 107-124, 2002. 
ARRUDA, Gilmar. A 'grande transformação' e a biota cultural das populações em movimento. Diálogos, Maringá, v. 14, n. 2, p. 287-303, 2010.

BALHANA, A. P.; MACHADO, B. P.; WESTPHALEN, C. M. História do Paraná. Curitiba: Grafipar, 1969.

BRASIL. Lei n. 12651/2012. Código Florestal Brasileiro. Disponível em: <www.planalto.gov.br/ccivil_03/_ ato2011-2014/2012/lei//12651.htm>. Acesso em 15 jun. 2015.

CANCIAN, Nadir Apparecida. Cafeicultura paranaense - 1900/1970. Curitiba: Grafipar, 1981.

FOGARI, Edna Regina Gomes. Norte do Paraná: um estudo dos movimentos de ocupação e sua recente história. Curitiba, 2009. Relatório (Programa de Desenvolvimento Educacional - PDE) - Secretaria de Estado da Educação, 2009.

GUBERT FILHO, Francisco A. 0 desflorestamento do Paraná em um século. In: SONDA, Claudia; TRAUCZYNSKI, Silvia Cristina (Org.). Reforma agrária e meio ambiente - teoria e prática no Estado do Paraná. Curitiba: ITCG, 2010, p. 15-25.

HAUER, Margit. As florestas no Paraná: um processo de involução. In: SONDA, Claudia; TRAUCZYNSKI, Silvia Cristina (Org.). Reforma agrária e meio ambiente - teoria e prática no Estado do Paraná. Curitiba: ITCG, 2010, p. 27-44.

HOLLING, C. S. Resilience and stability of ecological systems. Annual Review of Ecology and Systematics, v. 4, p. 1-23, sep. 1973. Disponível em: http://webarchive.iiasa.ac.at/Admin/PUB/Documents/RP-73-003.pdf. Acesso em 19 jun. 2015.

IBC-GERCA. Diversificação da estrutura agrícola das regiões cafeeiras - Plano Diretor. Brasília: Gerca, 1962.

Racionalização da cafeicultura brasileira - Programa de Renovação. Londrina: Agência do IBC, 1969.

KLABIN. Relatório sobre as áreas plantadas com Araucária, Eucalipto e Pinus, atingidas pelos incêndios de agosto/setembro-63. Jundiaí: Acervo do Centro de Documentação e Memória Klabin, 1963.

KOBIYAMA, Masato et al. Conceitos básicos. In: Prevenção de desastres naturais: conceitos básicos. Curitiba: Ed. Organic Trading, 2006, p. 7-30.

LOPES, Alfredo Ricardo Silva. A natureza do risco: paisagem e risco na análise dos desastres socioambientais. Esboços, Florianópolis, v. 20, n. 30, p. 52-66, dez. 2013.

MAACK Reinhard. Geografia física do estado do Paraná. Curitiba: Editora Max Roesner, 1968.

MEYER, Daniel. Transitions and resilience in the frozen commons. Linking aquaculture, krill fishery, governance and ecosystem change in the Scotia Sea, Southern Ocean. Stockholm, 2011, $103 \mathrm{f}$. Thesis (Master's Thesis in Ecosystems, Resilience and Governance) - Stockholm Resilience Centre, 2011.

. Nova forma de confrontar problemas ambientais no Brasil. Disponivel em: < http://www.oeco.org. br/convidados/25363-nova-forma-de-confrontar-problemas-ambientais-no-brasil>. Acesso em 28 jul. 2014.

MORO, Dalton Aureo. Substituição de culturas, modernização agrícola e organização do espaço rural no norte do Paraná. Presidente Prudente, 1991. Tese (Doutorado em Geografia) - Universidade Estadual Paulista, 1991.

MÜLLER, Nice Lecocq. Contribuição ao estudo do norte do Paraná. Geografia, Londrina, v. 10, n. 1, p. 89-118, jan./jun. 2001. 
NUNES, José Luiz Alves. 1963: o Paraná em chamas. Londrina: Ed. do Autor, 2013.

OLIVEIRA, Semí Cavalcante. A economia cafeeira no Paraná até a década de 1970. Vitrine da Conjuntura, Curitiba, v. 2, n. 4, p. 1-8, jun. 2009.

PARANÁ. O Paraná em flagelo: relatório. Curitiba: DGTC, 1963

. Paraná: do flagelo à recuperação. Curitiba: Departamento de Imprensa Oficial, 1964.

POZZOBON, Irineu. A epopeia do café no Paraná. Londrina: Grafmarke, 2006.

PRIORI, Angelo. O protesto do trabalho: história das lutas sociais dos trabalhadores rurais do Paraná (19541964). Maringá: Eduem, 1996.

SHIMIZU, Jarbas Yukio. Introdução. In: SHIMIZU, Jarbas Yukio (Org.). Pinus na silvicultura brasileira. Colombo: Embrapa Florestas, 2008, p. 1-5.

SILVEIRA, Leonor Marcon. A ocupação e organização espacial do território paranaense face aos recursos da natureza. Acta Scientiarum, Maringá, v. 20, n. 1, p. 129-136, 1998.

SOARES, Ronaldo Viana. Incêndios florestais - controle e uso do fogo. Curitiba: Fundação de Pesquisas Florestais do Paraná, 1985.

TUOTO, Marco; HOEFLICH, Vitor Afonso. A indústria florestal brasileira baseada em madeira de Pinus: limitações e desafios. In: SHIMIZU, Jarbas Yukio (Org.). Pinus na silvicultura brasileira. Colombo: Embrapa Florestas, 2008, p. 6-10.

ULTIMA HORA, Curitiba, 9 set. 1963.

VALASKI, Simone; NUCCI, João Carlos. Mapa Fitogeográfico do Paraná (MAACK, 1950): coleção de mapas como solução cartográfica. Anais do IV SLAGF, Maringá, v. 1, p. 1-10, 2006. 